\title{
Enredadera a dos voces, Los trazos del viento y Jauría: el teatro como medio de denuncia y lucha
}

\section{Resumen}

En este artículo se compararán las obras teatrales Los trazos del viento de Alan Aguilar y Jauría de Enrique Mijares. Para lo anterior el ensayo se dividirá en el estudio de los siguientes ejes: el repaso del marco teórico e histórico que rodea a los feminicidios cometidos en Ciudad Juárez; la naturaleza temática de las obras, donde se analizará la perspectiva con la cual los autores abordan la realidad representada; la naturaleza de los personajes, donde serán analizados los protagonistas de las historias para determinar su carga semiológica y metafórica; y la naturaleza social, vertiente en la que se expondrá la manera en la cual las obras de teatro estudiadas resultan en un medio para, a través de la ética y de la ideología de sus autores, realizar denuncias imperecederas y generar un impacto perceptivo en la mente de lectores o espectadores. Además, en este trabajo se observarán los motivos por los cuales los personajes funcionan como un medio sensible para representar una realidad inenarrable, a la vez que contribuyen al campo de la literatura mexicana mediante nuevos aspectos formales y discursivos.

Palabras claves

Teatro, literatura sobre el feminicido, literatura comparada, Ciudad Juárez, literatura de la frontera.

\begin{abstract}
In this article I will compare the theater plays Los trazos del viento by Alan Aguilar and Jauría by Enrique Mijares. This work will be divided in the study of the following axes: a review of both, the theoretical and historical frame surrounding the femicides perpetrated in Ciudad Juarez; the plays' thematic basis along with the authors' perspective on the narrated subject; the characters, specifically in their semiological and metaphorical significance in regards to the portrayed reality; and the social impact, scope in which it will be observed the ethical and ideological meanings used to denounce a painful reality and to provoke an impact in readers and audience. Furthermore, in this article I will expose why the characters work as a faithful representation of an unattainable reality, while contributing to the Mexican literature through formal and discursive aspects.
\end{abstract}

Keywords

Theater, femicide literature, comparative literature, Ciudad Juarez, border literature. 
Escritores nacidos en un México socialmente agonizante, han explorado una nueva temática literaria denominada "del feminicidio", la cual busca no sólo la reivindicación moral del país al cual alude, sino además e implícitamente, un cambio profundo y sustancial dentro de la corriente de la literatura mexicana. Este artículo se propone comparar las obras de teatro Los trazos del viento, de Alan Aguilar, y Jauría, de Enrique Mijares, textos que para su construcción, utilizan como tema los feminicidios perpetrados en Ciudad Juárez. La selección de tales obras obedece a que mientras la de Aguilar retrata a las víctimas, la de Mijares hace lo mismo con los victimarios, de modo que a la vez que son opuestas, se complementan.

Antes de entrar de lleno en el análisis de dichos textos, resulta necesario indagar en el marco histórico que dio pie a la existencia de su temática. De tal modo, realizar una aproximación al significado de la palabra "feminicidio", se consolida como el primer punto por abordar. Sobre dicho tema, Rita Laura Segato recuerda que uno de los primeros referentes para la definición del término, se encuentra en el texto Femicide de Jane Caputi y Diana Rossell, quienes señalan que:

El feminicidio representa el extremo de un continuum de terror antifemenino e incluye una amplia variedad de abusos verbales y físicos,

${ }^{1}$ Temática que no es exclusiva de la literatura, pues también ha sido explorada en creaciones "pictóricas, escultóricas, musicales, fotográficas, teatrales, cinematográficas [y en] los medios de comunicación, [como] la prensa, la radio y la televisión" (Lagarde 211), algunos de los trabajos más destacados que han abordado la temática del feminicidio, serán mencionados durante el desarrollo de este artículo.

${ }^{2}$ Debido a que el objetivo de este trabajo consiste en realizar un análisis literario de las obras mencionadas, sólo se otorgan algunas de las principales definiciones emitidas por distintas especialistas en la materia. El que no se realice un análisis profundo sobre los orígenes y debates que en torno al feminicidio han surgido, obedece a que, como Rita Laura Segato afirma, "se trata de una discusión reciente, sin inscripción en la bibliografía" (35), por lo que exigiría una investigación más extenso que se dedicara exclusivamente a su estudio. 
tales como violación, tortura, esclavitud sexual [...] abuso sexual infantil incesutoso o extrafamiliar, golpizas físicas y emocionales, acoso sexual [...] mutilación genital [...] operaciones ginecológicas innecesarias [...] heterosexualidad forzada, esterilización forzada, maternidad forzada [...] psicocirugía, negación para comida de mujeres en algunas culturas, cirugía plástica y otras mutilaciones en nombre del embellecimiento. Siempre que estas formas de terrorismo resultan en muerte, se transforman en feminicidios. (36)

Estos actos de odio se configuran con base en una dicotomía de género en la cual el rubro femenino es violentado por el masculino, hecho sobre el cual Russell y Radford afirman, el feminicidio es un "asesinato misógino de mujeres por hombres" (cita en Monárrez 36); en este punto es importante aclarar que no todos los homicidios de mujeres cometidos por el género opuesto deben considerarse feminicidios, sino sólo aquellos que fueron realizados "porque se es una mujer" (Dworkin, cita en Monárrez 36).

De acuerdo con la investigación sobre el tema realizada por Julia Monárrez, los motivos por los cuales el feminicidio es cometido, "pueden ser el odio, el placer, la ira, la maldad, los celos, la sensación de poseer y controlar a la mujer y exterminar a quien es considerada inferior" (36). Tales motivos encuentran su punto de partida en un sistema patriarcal dominante ${ }^{3}$, que en el caso de Ciudad Juárez, durante el apogeo de los feminicidios (1993-2005) ${ }^{4}$ se hizo evidente con pronunciamientos como el del exsubprocurador Jorge López Molinar quien, como recuerda Tabuenca Córdoba, durante su gestión afirmó que "todas las [víctimas] eran vagas y hasta prostitutas" (416). Sentencia que permite

${ }^{3}$ Sobre el cual Julia Monárrez afirma, "sabemos que existe todo un sistema de relaciones de poder (económico, social, político, judicial y religioso) que nos cruza como mujeres y hombres, pero que en este orden se favorece lo masculino y se deja en desventaja lo femenino. Las instituciones sociales y políticas están en manos de los poderes patriarcales" (43).

${ }^{4}$ Período en el cual coinciden Diana Washington Valdez y Julia Monárrez en sus textos aquí citados. 
identificar la manera en la cual se justifican los asesinatos al inculpar a las víctimas, pues "el uso de la preposición 'hasta' como sinónimo de 'inclusive' le sirve a López Molinar para enfatizar el discurso subyacente 'se lo buscó"' (417), elemento con el cual se comprueba que

en un medio dominado por la institución patriarcal, se atribuye menos valor a la vida de las mujeres y hay una propensión mayor a justificar los crímenes que padecen. (Segato 37)

De tal modo, los feminicidios tienden a estar permeados por ciertas condiciones sociales que resultan definitivas para perpetrar tal ideología patriarcal y con ella, la impunidad, pues "para que se dé el feminicidio concurren, de manera criminal, el silencio, la omisión, la negligencia y la colusión parcial o total de autoridades" (Lagarde 216). Dicha premisa resulta especialmente relevante para el análisis de Jauría, obra en la cual, como será visto en este trabajo, la omisión y la colusión son elementos determinantes para el desarrollo de la trama.

Debido a que las obras por analizar refieren específicamente a los feminicidios cometidos en Ciudad Juárez, vale la pena entonces, con el objetivo de otorgar un panorama más claro sobre el asunto que tratan, recordar algunos de los principales detalles de este contexto histórico. Específicamente,

en 1999, los asesinatos de mujeres estaban en su apogeo. Entre 1993 y 2005 , fueron asesinadas alrededor de quinientas niñas y mujeres, $[\ldots]$ en un informe del gobierno federal mexicano, en enero de 2006 se reconocieron alrededor de 400 víctimas. Según la doctora Julia Monárrez [...] las mujeres eran jóvenes y fueron violadas antes de ser asesinadas de manera brutal. (Washington 54) 
Las académicas hasta aquí mencionadas, coinciden en que las víctimas "son predominantemente mujeres jóvenes, morenas, estudiantes, obreras, niñas, y todas son económicamente marginales" (Monárrez 49), elementos que como será visto unos párrafos más delante, son utilizados por Alan Aguilar para construir a sus protagonistas. Sobre los motivos por los cuales Ciudad Juárez ha enmarcado tan lamentable cantidad de feminicidios ${ }^{5}$, Monárrez señala a "la ciudad como polo de atracción para poblaciones inmigrantes; el proceso de industrialización [...] y la alternancia antidemocrática en el aparato estatal" (71).

De tal modo, Ciudad Juárez resulta atractiva para los migrantes nacionales y centroamericanos, debido a que éstos tienden a dejar su lugar de origen con el anhelo de llegar a Estados Unidos buscando una mejor vida (71); la razón por la cual se desplazan principalmente a dicha ciudad y no a Tijuana, que es también frontera norte, se debe a que

en Tijuana el cruce tanto en automóvil como a pie es más complicado [...] San Diego queda a por lo menos 40000 kilómetros de distancia [...] Ciudad Juárez y El Paso son geoespacialmente concebidas como metrópolis [...] y no hay una distancia mayor a la de los puentes internacionales entre una ciudad y otra (aproximadamente doscientos metros). (Tabuenca 422)

Fue así como los migrantes que a finales de los 80 se asentaron en Ciudad Juárez con la esperanza de cruzar "al otro lado", llegaron a conformar cerca del 25 por ciento de la población de dicha zona (Monárrez 72). La principal fuente de trabajo para ellos y en general para la población en situación de pobreza, ha sido

\footnotetext{
${ }^{5}$ Los que sin embargo, "en 1999 [...] se habían extendido a la capital chihuahuense. [Además], también en otros lugares de la República mexicana se reportaron feminicidios que seguían un patrón similar. [Incluso], hubo un diagnóstico legislativo sobre las muertes nacionales, pero esto no ayudó a establecer líneas de investigación" (Washington 62-63).
} 
la industria maquiladora, la cual se ha caracterizado "en los bajos salarios y pocos beneficios ofrecidos $[\ldots]$ especialmente a sus obreras" (73).

Aunados al flujo de migrantes que llegaban a Ciudad Juárez con el objetivo de cruzar la frontera, se incluyen quienes se dirigían a dicha ciudad. Lo anterior se debe a que, aunque en principio el crear industrias maquiladoras ${ }^{6}$ en la zona norte fronteriza tenía el objetivo de atraer a los mexicanos que sin documentos se habían ido a trabajar a Estados Unidos, éstos no regresaron y en cambio, fueron principalmente mujeres del sur del país quienes se desplazaron a tal territorio al ver la oportunidad de encontrar ahí un trabajo fijo (Tabuenca 433),

the maquiladoras had attracted women from all over Mexico, providing enough jobs to attract a pool of young women, many of whom lived in shanty towns on the outskirts of the city (Franco 219)

De tal modo, la industrialización que en Ciudad Juárez trajo consigo la hegemonía de la maquiladora otorgó "nuevas posibilidades de empleo para las mujeres" (Tabuenca 413), quienes hasta antes de 1965, sólo se habían desempeñado como amas de casa, meseras, secretarias, empleadas domésticas o sexoservidoras (412-413). Esta nueva condición de la joven mujer obrera, la dotó de una aunque precaria, verdadera "autonomía económica", con la cual "pasó de 'la hija' o 'la hermana' a ser la proveedora del hogar" (413). Sin embargo, este proceso de transición, como señala Ileana Rodríguez, trajo consigo condiciones de trabajo riesgosas para las empleadas de las maquiladoras,

There is only a long, empty, and threatening corridor between the maquila and home. Leaving the house at dawn, returning in the middle of the night, walking through dark and empty streets, parks, or neighborhoods, riding

\footnotetext{
${ }^{6}$ Proyecto denominado "Programa de Industrialización de la Frontera", el cual se puso en marcha en 1965. (Tabuenca 413, 433)
} 
an empty bus, not no mention the journey from southern to northern Mexico . (ch. 7)

A tal situación de riesgo se añade otro factor que ha contribuido con la impunidad en la cual los feminicidios se mantienen: las empleadas de las maquilas se hicieron independientes, de modo tal que comenzaron a participar en "spaces and times that were socially assigned to men" (ch. 7), hecho que desembocó con la creación del "estereotipo de la obrera maquiladora como mujer de dudosa reputación" (Tabuenca 413), pues de un rol pasivo, adquirió uno plenamente activo, transgrediendo así "los espacios y las costumbres" (413).

De tal modo, los anteriores fueron dos de los elementos principales que contribuyeron a convertir a Ciudad Juárez en un escenario idóneo para los feminicidas, quienes por un lado, en los horarios y rutas establecidos por las maquiladoras encontraron los medios para cometer gran parte de los secuestros, "the killers took advantage of the terrain, the dusty deserted roads leading the poorly lit streets on which women walking home were a convenient prey of the bitter and resentful male" (Franco 223); y por el otro, hallaron refugio en el discurso emitido por el aparato estatal que, en lugar de perseguirlos, han culpado a las víctimas al juzgarlas y poner en duda su calidad moral con asunciones tales como que "las obreras de maquiladora no son tan 'buenas' y 'decentes' como las de la clase media y alta, "por eso las matan"” (Tabuenca 420). Con tales acciones, -las corporales y las discursivas-,

no sólo se asesina el cuerpo biológico de la mujer; se asesina también todo lo que ha significado la construcción cultural de su cuerpo, con la pasividad y la tolerancia de un Estado masculinizado. (Monárrez 86)

Es necesario señalar que los párrafos anteriores sólo son introductorios y otorgan algunos datos que apenas y contribuyen a dar una idea sobre la 
problemática del feminicidio ocurrida en Ciudad Juárez, la cual ni ha terminado, ni es exclusiva de dicha región pues sucede también a nivel nacional y global ${ }^{7}$. Sin embargo, no se puede negar que debido al alarmante número de asesinatos de mujeres en un período tan específico, Ciudad Juárez ha sido "noticia obligada de los principales diarios del mundo" (Tabuenca 411) y que además ha dado pie a la creación de diversas manifestaciones culturales que se han concentrado en la temática del feminicidio.

De entre la producción cultural que desde diferentes puntos de vista ha tratado el tema de los feminicidios cometidos en la frontera norte del Estado de Chihuahua, están las novelas 2666 (2004), de Roberto Bolaño; KRTM Snuff movie (2007), de Ricardo Clark y Sangre en el desierto (2008), de Alicia Gaspar de Alba. Además, están los trabajos periodísticos y de investigación Las muertas de Juárez: crónica de una larga pesadilla (1999), de Víctor Ronquillo; Huesos en el desierto (2002), de Sergio González Rodríguez y Cosecha de mujeres: safari en el desierto mexicano (2005), de Diana Washington, por mencionar sólo tres de los muchos trabajos de investigación que al respecto se han realizado (algunos más forman parte de la bibliografía de este trabajo).

En la escultura destacan las obras de Manolo Gallardo, mientras en el rubro de la pintura el tema ha sido abordado por los artistas Oscar Desfassiaux con "El cuadro peregrino" (2005); Sandra Sandoval con "Feminicidios" (2007); y Mina Hamada con "Mujer transparente flor" (2013); entre muchos otros. Por su parte, los poetas Roberto Ruiz Antúnez, Arminé Arjona y Manuel González también han incluido a esta temática en su obra creativa.

En el cine, el tema ha sido trabajado en las películas Bordertown (2006), de Gregory Nava; The virgin of Juarez (2006), de Kevin James Dobson; El traspatio (2009), de Carlos Carrera; y en el documental Señorita extraviada (2001), de Lourdes Portillo; nuevamente, por mencionar sólo algunos ejemplos.

${ }^{7}$ Estadísticas y datos más precisos de esta problemática se encuentran en "Antropología, feminismo y política: violencia feminicida y derechos humanos de las mujeres", de Marcela Lagarde y en el capítulo 9 de Cruel Modernity de Jane Franco. 
En un caso más reciente, el mismo tema se convirtió en el argumento principal de la serie televisiva The Bridge (2013), creada por Elwood Reid, Björn Stein y

\section{Meredith Stiehm.}

El teatro tampoco ha permanecido indiferente a dicha problemática y entre las obras que la abordan se encuentran ${ }^{8}$, La vida vale, de Victoria Martínez; Memoria de duelo, de Rocío Galicia; Sirenas de río, de Demetrio Ávila; Lomas de Poleo, de Edeberto Galindo; Justicia Light, de Ernesto García; La ciudad de las moscas, de Virginia Hernández; Mujeres de Ciudad Juárez, de Cristina Michaus; Hotel Juárez, de Víctor Hugo Rascón Banda; Estrellas enterradas, de Antonio Zúñiga; Tlatoani (Las muertas de Suárez), de Juan Tovar; y Desere (El desierto), de Cruz Robles.

Como es posible observar, "notorious crimes are rapidly fictionalized or adapted to the cinema" (Franco 1-2), hecho que ha sido motivo de sendos debates debido a la posibilidad de que tales manifestaciones culturales estén lucrando con el dolor ajeno al mismo tiempo que lo banalizan, como sucede en el siguiente ejemplo estudiado por Jane Franco,

the young women murdered in Ciudad Juarez was scarcely cold in their graves before a feature film, Bordertown, was released, with its sickening vulgarization of the murders. (2)

Sin embargo, si bien es cierto que, como afirma Ramón Gerónimo Olvera -concordante con lo expuesto por Franco-, actualmente "la puerta de muchos editores es golpeada por un importante número de escritores, $[\ldots]$ que con ríos de sangre en sus tramas pretenden ingresar al mundo de las letras" (26), también resulta verdadero que existen representaciones que contrario a vulgarizar los

\footnotetext{
${ }^{8}$ Las obras de teatro aquí mencionadas forman parte de la antología realizada por Enrique Mijares, titulada Hotel Juárez: dramaturgia de feminicidios, la cual fue publicada en 2008 por Union College, la Universidad Juárez del Estado de Durango, el Consejo Nacional para la Cultura y las Artes y Siglo Veintiuno Editores.
} 
hechos, pueden renovar la sensibilidad y el interés en ellos. Lo anterior es lo que logran las obras de teatro Los trazos del viento, de Alan Aguilar y Jauría, de Enrique Mijares, las cuales son el objeto principal de este análisis.

Los mencionados autores, son dramaturgos mexicanos que al abordar el tema del feminicidio mediante el teatro, lo han sabido reconocer como un medio de denuncia. Si bien es cierto que todas las manifestaciones artísticas tienen el poder de generar cambios en las conciencias de quienes las contemplan, es la dramaturgia la que nunca ha intentado ocultar su carácter social. Tal hecho queda manifiesto desde sus orígenes en la antigua Grecia, cuando el teatro buscaba el adoctrinamiento religioso o político; aunque es cierto que ha evolucionado, en la actualidad el arte teatral sigue siendo una herramienta social en tanto se ha legitimado como medio de crítica, denuncia y develo.

Lo anterior puede ejemplificarse con las obras seleccionadas, textos donde los personajes se erigen como los principales elementos para, mediante su construcción alegórica, representar no sólo a los protagonistas, sino además, a las situaciones y a las ideas que han permeado al espacio narrado, este es, Ciudad Juárez.

Por lo tanto el siguiente análisis, que toma como marco teórico las ideas en torno al feminicidio previamente ilustradas, tiene como objetivo demostrar que los personajes estudiados funcionan como un medio fiel de representación de las víctimas y de los victimarios de los feminicidios cometidos en Ciudad Juárez, pues ambas recogen y se apegan a sus más esenciales características ${ }^{9}$, enunciadas por las académicas e investigadoras anteriormente citadas.

Por lo anterior, resulta necesario estudiar la anécdota de las obras, entendiéndola como la historia relatada, como la diégesis del drama. Helena Beristáin define a esta última como la "sucesión de acciones que constituyen los

\footnotetext{
${ }^{9}$ Mismas que fueron mencionadas durante el desarrollo del marco teórico e histórico y en las que se hará especial énfasis cuando se identifiquen en el plano literario. Cabe también señalar que aunque los autores a ellas se apegan, son estilizadas con ciertos recursos literarios a identificar durante el desarrollo de este análisis.
} 
hechos relatados en una narración o en una representación" (149). De tal modo, en este punto hace falta realizar el recuento de las acciones llevadas a cabo por los protagonistas y la interpretación de las mismas equiparada al plano de la realidad.

En Los trazos del viento no es posible hablar de una cadena de acciones que devengan en hechos determinados, pues debido al clima de monotonía en el cual los personajes residen, la historia se construye con base no tanto en lo que hacen, sino en lo que dicen. Por lo previo, el análisis de la historia de esta primera obra, se centrará en lo dicho por las protagonistas, pues son las palabras quienes revelan la verdadera trama en la cual los personajes habitan.

El feminicidio como tema literario es abordado por Aguilar desde el punto de vista femenino, por lo cual el autor se vale de una narrativa de extrema sensibilidad y tono suave, doloroso y poético, para relatar el que pareciera un día que los simboliza a todos en la vida cotidiana de tres mujeres. Estos personajes se configuran primero como víctimas de la pobreza, luego de la cultura patriarcal y por último de un asesino cruel que se intuye y simboliza en la figura del viento, dichas situaciones se manifiestan en la voz de Laura niña de los niños:

Como siempre, todo tan caro que parece que sólo ganas para dejar todo en un mandado. No alcanza para nada. Lo poquito que una gana y encima te lo quitan también allá. Quesque para tu bonito retiro, que para la tanda de no sé qué. Y luego todo en el mercado, o el mol como le dicen por acá. (66)

Alan Aguilar no deja espacio para las obviedades, los personajes y las situaciones a las cuales éstos están sujetos, son construidos a partir de indicios que empujan al lector a que descubra cómo es la realidad narrada. En la cita anterior no fue necesario insertar el término "maquiladora" para que se adivinara que Laura es empleada de una. Bastaron unas cuantas referencias sobre situaciones 
inherentes a dicho espacio de trabajo para, teniendo como referencia el contexto de la obra, dejar tal elemento al descubierto.

Aunados al tema de la maquiladora, se encuentran los temas de la pobreza, “caro, caro, caro, todo más caro por acá" (Aguilar 66); los de la explotación laboral, "estar todo el día como burra, sacando y metiendo, metiendo y sacando, subiendo y bajando, bajando y subiendo ... para sanciones, multas" (66); los de la falta de seguridad para las empleadas, "¿por qué trabajar de noche ...? ... a esa hora ya no le dan nada a nadie. Ni transporte ni nada y eso que es cuando más lo deberían de dar" (67); y los de la desigualdad de género, "contratan a todas las solteras y despiden a todas las que se enteran que están embarazadas" (67).

Es justamente la desigualdad de género, uno de los elementos que mayor presencia tienen en la obra. La opresión patriarcal a la cual están sujetas las protagonistas se configura como un elemento fundamental en su presente doloroso. Dicha situación se evidencia cuando Laura, al referirse a los hombres expresa,

como si ser mujer fuera estar sola ... [los hombres] se la pasan pensando en ellos todo el tiempo ... mejor sería que se quedaran chiquitos ... sin toda esa cosa negra que les va deshaciendo el alma. (61-68)

De tal modo, en el texto se añora la infancia durante la cual los sujetos aludidos desconocían las relaciones de desigualdad y poder y aún no participaban de ellas. Sin embargo, en este punto es necesario destacar que aunque las aseveraciones de las protagonistas están encaminadas a evidenciar posiciones machistas, éstas tienden a referir a sujetos específicos y no necesariamente a todo el género masculino, como queda claro cuando Lucía señala, "para no tener que aguantar las miradas de ésos. Del mentado supervisor y de sus achichincles. Si hasta parece que nos quisieran devorar" (67). 
Por lo tanto, durante el análisis de esta obra se debe tener en cuenta que las protagonistas aluden a un contexto determinado: el del ambiente en la maquiladora. En dicho espacio la postura machista-patriarcal se hace obvia en tanto el género masculino es el que suele ostentar los cargos más altos, mientras el femenino, por lo general ocupa los más bajos. Escenario que crea relaciones de desigualdad colocando a la mujer en claras situaciones de desventaja.

Al clima de pobreza, abuso laboral y desigualdad en las vidas de los personajes, Aguilar añade las más crueles y determinantes repercusiones de la violencia llevada al extremo, la cual se advierte favorecida con los señalados elementos. Tales repercusiones se articulan sobre el descubrimiento de que las protagonistas de Los trazos del viento están muertas, calidad revelada en las enunciaciones de añoranza que por el mundo las protagonistas realizan, "qué ganas de estar otra vez allá. De volver a ver las plantas y volver a ver el mar con su agüita tibia" (68).

El quiebre emocional que puede provocar la obra, se multiplica al descubrir que los personajes narrados no sólo están muertos, sino que además, padecen en una suerte de purgatorio desértico que bien podría ser la alegoría de sus cuerpos perdidos en la arena, "acartonado[s] por el sol” (Monárrez 84), en tanto reflejan los restos de las víctimas de los feminicidos cometidos en Ciudad Juárez, a quienes "la arena se les met[e] por todos lados... Donde el calor y el frío son cómplices del viento" (63).

Los elementos con los cuales Aguilar construye a las protagonistas de su obra, descritos unas líneas atrás, les otorgan mayor veracidad al tener como marco previo la descripción que las investigadoras citadas realizan sobre las víctimas; descripción en la cual, hay que recordar, existe un consenso en torno a que se trata de obreras de maquiladora en situaciones marginales, subyugadas por una cultura patriarcal que se antoja impenetrable, cuyos cuerpos sin vida generalmente eran "left in empty lots, uninhabited zones, rivers, canals, roads, garbage dumps, parks, cemeteries, and cotton fields" (Rodríguez ch. 7). 
Por lo tanto, es posible inferir que la trama de la obra de Aguilar no obedece a acciones, sino al estatismo que induce a los personajes a relatarse mediante indicios, sentencias y añoranzas nacidas en la oquedad de un limbo imaginado. Aguilar dotó a sus personajes de una voz que no entra en detalles para contar su historia. Un elemento interesante en la construcción de esta obra, resulta en que las protagonistas están llenas de vida,

¡Yo nada más junte mi dinero y voy a desaparecer! Me voy a ir muy lejos... A cruzar el mar. A conocer otras tierras y otras gentes, otro lugar. A ver otros amaneceres y otros atardeceres. A probar frutas nuevas. (62)

El anterior es uno de los mayores aciertos del dramaturgo, quien en lugar de intentar retratar actos de violencia física que además son inenarrables -como los momentos de la persecución o de los asesinatos-, prefiere presentar a las víctimas en la plenitud vital que les intuye. En una puesta en escena llevada a cabo en el Foro Nacional de las Artes en 2008, las actrices cantaban, bailaban y sonreían constantemente para interpretar a los personajes, hecho que contribuyó al impacto en el espectador ante el descubrimiento de que los planes de las protagonistas eran irrealizables y de que su vida era falsa porque estaban muertas.

Contrario a lo realizado por Alan Aguilar, quien en Los trazos del viento da voz a las víctimas, Enrique Mijares, en Jauría narra las historias de violencia y crimen de por lo menos cuatro grupos de feminicidas. Dentro de la narración, tales conjuntos se advierten distintos en sus motivos y modos, pero en su maldad similares, pues forman parte de una jauría, o bien, de una cofradía ${ }^{10}$ fortalecida en la criminalidad imperante de Ciudad Juárez.

La comparación de las obras aquí estudiadas se erige en la oposición sobre la cual se presentan las acciones, distinto al estatismo ostentado por las

${ }^{10}$ Término utilizado por Rita Laura Segato en el artículo Qué es un feminicidio para describir la relación existente entre los hombres perpetradores y auspiciadores de los feminicidios en Ciudad Juárez. 
protagonistas de Aguilar, en Jauría los diálogos son abrumadoramente dinámicos. Si en la primera obra analizada las acciones deben ser imaginadas por el lector, en este segundo texto, la imaginación no hace falta debido a la fuerza de los diálogos. Un elemento interesante es que pese a las diferencias entre una y otra obra, ambas comparten la ausencia de acciones, mientras en la primera éstas deben identificarse a través de indicios, en la segunda, éstas están contenidas en los diálogos.

La historia relatada por Enrique Mijares se articula desde la perspectiva patriarcal, machista, violenta e inhumana de los delincuentes. Ausente de personajes femeninos, la obra permite entrever algunos de los que pudieron ser los estímulos de los feminicidas para cometer sus crímenes: la posibilidad de la creación de redes de pornografía, rituales satánicos, el rechazo a las mujeres independientes, problemas domésticos y/o el odio al género opuesto.

En el punto anterior radica uno de los principales argumentos por el cual, es posible afirmar que la obra de Mijares es consistente con una representación fidedigna de los victimarios, en tanto se apega a algunos de los más recurrentes perfiles de los criminales emitidos por las investigadoras aquí citadas, como será demostrado en el avance de este estudio.

En las primeras líneas de Jauría, las acciones son relatadas a través de un diálogo sostenido por dos de los actantes centrales de la historia: El Chacal y La Rata. Dicho diálogo tiene como preámbulo una acotación que describe a los protagonistas mientras "duermen entrelazados al cadáver de la jovencita" (189), sentencia con la cual queda establecida la acción previa cometida por tales personajes: el asesinato.

Antes de entrar de lleno en las acciones descritas por los diálogos, resulta necesario recordar la relación entre lenguaje y sociedad puntualizada por Norman Fairclugh, para quien: 
"Social phenomena are linguistic, $[\ldots]$ in the sense that language activity which goes on in social contexts [...] is no merely a reflection or expression of social processes and practices, it is a part of those processes and practices" (19).

Para el teórico la relación existente entre lenguaje y sociedad puede explicarse a través -más no únicamente- de las ideologías, las cuales utilizan al discurso como camino a la mente y conducta humana. Fairclough afirma que el discurso aparece cuando el lenguaje es utilizado como una práctica social, razón por la cual asegura que el binomio lenguaje y sociedad mantiene una "internal and dialectical relationship" (19).

De tales afirmaciones cabe establecer que, por lo tanto, el discurso enunciado por los protagonistas de Jauría, puede y debe ser considerado como una expresión irreductible a un mero acto comunicativo entre los personajes, y que además, debe tomarse como parte fundamental de las acciones en la obra descritas, como acción misma.

La premisa anterior es sostenible a partir de las ideas expuestas por Fairclough en las cuales se establece que, cuando el lenguaje interviene en la sociedad, al tener impacto en el pensamiento, se convierte en actividad, en práctica e incluso en método para obtener y mantener el poder. Por lo tanto, el lenguaje debe ser incluido para el análisis de las acciones de los planos real y ficcional representados en la obra abordada.

El lenguaje utilizado por los protagonistas de Jauría revela la ideología patriarcal y las estructuras de poder a las cuales el marco histórico introductorio se adhiere:

RATA: ¿La oíste gemir y suplicar?

CHACAL: Decía algo, lo repetía sin parar.

RATA: Era su nombre. 
CHACAL: Para que no se le olvidara.

"RATA: Gabriela, Elsa, Margarita... Eso qué importa.

CHACAL: Hay que llevar la cuenta, eso sí. (193)

En el diálogo previo, los personajes nulifican a su víctima mediante el desconocimiento y la indiferencia hacia su nombre, acción que como Julia Monárrez señala, en las mentes de los victimarios demuestra "el valor de deshecho de quien careció de posición y privilegio" (63).

Por lo anterior es posible observar, en términos de Rita Laura Segato "los dos ejes de interlocución" en los que participan víctimas y victimarios. El primer eje, competente a "las posiciones asimétricas entre poder y sujeción, o sea, del perpetrador con su víctima" (37) fue recién expuesto, edificado por Mijares en la indiferencia y en la inhumanidad con la que los feminicidas actúan. Por lo tanto, desde aquí es necesario establecer un enfoque hacia el segundo eje, el cual, consiste en la manera "en que se vincula el perpetrador con sus pares, en una relación que intenta ser simétrica" (38) y de la que Jauría está poblada.

Durante el desarrollo de la trama de la obra de Enrique Mijares, la audiencia se enfrenta a una comunidad de hombres que se identifican en sus crímenes de odio hacia las mujeres. Sin embargo, tal jauría admite no sólo a los asesinos, sino además, a todos aquellos sujetos que, concordantes con la ideología patriarcal, minimizan los actos homicidas y de tortura, a extremo tal de proteger a los criminales, "the killings were a symptom of deep-rooted misogyny and ... the perpetrators were untouchable and beyond the rule of law" (Franco 221). Lo anterior se ejemplifica con el caso de los agentes de la policía personificados en el texto:

"AGENTE 4: Aquí no hay nada.

AGENTE 5: Ya se las comieron los zopilotes" (195) 
Aunque ninguno de estos agentes ha cometido un feminicidio, la actitud burlona con la cual acuden a las escenas del crimen los vuelve partícipes del entramado de horror que permea y permite la injusticia. Al no mostrar sensibilidad ante los cuerpos mutilados que encuentran en el desierto, los agentes envían un discurso de inhumanidad y desesperanza, pues con su falta de sorpresa, reciben como "cotidianos" semejantes actos de frialdad y odio, para los cuales el encuentro con la justicia se prevé todavía muy lejano.

Dentro de la trama de Jauría, vale la pena detenerse en la conversación entre el taxista denominado Gavilán y dos de sus pasajeros, en la cual el primero relata con orgullo cómo asesinó a su primera víctima:

GAVILÁN: Venía huyendo, me dijo. Bien lastimada. Llena de sangre. Tiras de piel, en los vidrios de la barda. Tenía las piernas destrozadas. Calmada, pequeña, conmigo estás a salvo. Y la subí al taxi (200)

En la cita anterior, es posible vislumbrar la hermandad en la que se desenvuelven tanto los criminales, como los observadores u oyentes pasivos de las transgresiones, quienes, con su omisión y morbo, contribuyen a alimentar la impunidad y la injusticia. Tal cofradía, en donde las acciones violentas de unos son aplaudidos y hasta admirados por los otros, funciona como una especie de virus que se contagia, donde, como afirma Segato, "no es a la víctima a quien dirigen su discurso los perpetradores, sino a sus pares en una demostración de capacidad de muerte y de crueldad probada en la víctima" (7). Además, tal demostración les supone el boleto para ingresar en la jauría de la violencia, para consumarla, protegerla y perpetuarla.

Si bien no es posible afirmar que estos personajes relatan la verdad de los protagonistas o de las situaciones de los feminicidios cometidos en Ciudad Juárez, pues, por un lado, "las investigaciones no han podido dar respuestas a casi 
ninguna pregunta ni a la mayoría de los crímenes que se siguen cometiendo" (Tabuenca 421) y, por el otro, "violence is not only beyond politics, but also beyond representation" (Franco 248), ni siquiera si se hubieran resuleto los casos, crímenes tan inhumanos como estos feminicidios pudieran haberse representado verídicamente -en el sentido amplio del término-, pues aunado a la violencia, el dolor está también más allá de toda representación.

Sin embargo, es posible afirmar que las obras de teatro aquí estudiadas, a diferencia de otras producciones culturales que sólo han explotado y banalizado al tema, como para Jane Franco sucede en "Bordertown, which featured Jennifer López as a fearless reporter, is an example of the inadequacy of a plot device that requires a single heroin and villain to tell a story where the murderers and victims are a multitude" (223), incluyen un panorama más amplio (en vez de simplificar un fenómeno que con dicha simplificación se banalizaría -el cual es el caso del ejemplo anterior-), en el que toman en cuenta los principales perfiles de las víctimas y de los victimarios protagonistas de los feminicidios; en un primer contraste entre el filme aludido y las obras de teatro analizadas, destaca el hecho de que mientras en Bordertown las protagonistas sobreviven - una de ellas con apenas escasos daños psicológicos-, tanto en Jauría como en Los trazos del viento, las víctimas siempre mueren o están muertas, elemento que resulta de mayor apego a la realidad narrada; un segundo contraste resulta en el destino de los victimarios, si en el filme éstos son castigados mortalmente, en las obras salen impunes; nuevamente, las obras de teatro se apegan con mayor fidelidad a los eventos verdaderos.

De tal modo, queda manifiesto cómo en Los trazos del viento y en Jauría, es posible encontrar si no la exactitud, por lo menos sí acercamientos fidedignos a los perfiles de las y los protagonistas de los feminicidios cometidos en Ciudad Juárez. Alan Aguilar retoma el perfil de la mujer obrera, empleada de una maquiladora que no provee situaciones seguras de trabajo y que además, se desenvuelve en un ambiente patriarcal que en lugar de perseguir a los criminales, criminaliza a las víctimas; circunstancias que desembocan en su asesinato y en el 
abandono de su cuerpo en el desierto, pues "danger coupled with impunity serves as aphrodisiac to murderers" (Rodriguez ch. 7).

Por su parte, Enrique Mijares, desde la perspectiva de los victimarios, retoma algunas de las teorías que sobre los móviles de éstos se han generado en distintos trabajos de investigación, tales como "the traffic of images and pornoviolence, sacrificial rites, or quarrels between gangs and polleros" (Rodríguez ch. 7). El tráfico de porno-violence o cine snuff, en la obra es realizado por un grupo de individuos liderados por el Zorro, quien antes de comenzar una filmación, indica a sus cómplices, "la muchacha es lo principal, ustedes son verdugos sí, pero son secundarios. Ella lleva el primer plano" (209).

La teoría sobre los feminicidios como parte de ritos satánicos, es encarnada por el Chacal y la Rata, hecho que puede apreciarse cuando el segundo señala, "si quiero convertirme en curandero, debo encontrar setenta mujeres y beberme cada gota de su saliva" (223). La disputa entre pandillas y polleros, es recreada con la pelea que tienen el Zorro y el Coyote, cuando el segundo asesina brutalmente a la hija del primero por una venganza personal.

A tales representaciones, se añade la doméstica, donde un hombre dice que asesinó a su esposa debido a que "las mujeres acaparan trabajos que eran de [los hombres] ... [mi esposa] me reclamaba: yo soy la que pago los abonos de la casa" (215). En el fragmento anterior es posible apreciar que cuando "women take over formerly masculine spaces" (Rodríguez ch. 7), los feminicidios se llevan a cabo "not only [with] sadistic enjoyment, but also [with] extreme rage against the female" (Franco 219).

En este punto es importante profundizar en los simbolismos que respaldan la construcción de los personajes de ambas obras estudiadas. Luz Aurora Pimentel afirma que el punto de partida para la individuación y la permanencia de un personaje a lo largo de cualquier narración es el nombre, pues es esta característica la que representa el centro de imantación semántica de todos los atributos de tal o cual personaje, el referente de todos sus actos y el principio de 
identidad que permitirá reconocerlo a través de todas sus transformaciones (63$64)$.

Al partir de la idea previa es posible establecer que, al analizar los nombres de los participantes de ambas obras de teatro, el entendimiento de la intencionalidad de las mismas será mucho más amplio. En el caso de Los trazos del viento las protagonistas llevan los nombres: Lucía Niña de los Canarios, Laura Niña de los Niños y Elena Niña de las Esferas. La personalidad con la cual Aguilar quiso imbuir a sus personajes es por demás identificable pues, al utilizar el sustantivo niña para las tres, las infantiliza casi al grado de purificarlas.

Luego, el autor agregó los términos canarios, niños y esferas, cuya musicalidad y sentido poético es más que evidente. Con dicha representación, Aguilar logró utilizar los nombres de sus personajes como símbolos de inocencia y de bondad, idea que a todas luces el autor mantiene sobre las mujeres victimizadas en Ciudad Juárez.

En el caso de Jauría, el autor no pudo ni siquiera dotar a sus personajes principales de un nombre humano. Las denominaciones a partir de las cuales éstos fueron construidos, se componen o bien, de un compendio de apodos con connotaciones violentas, o de nombres de animales salvajes y carroñeros. Chacal, Rata, Hiena, Coyote, Zorro y Sabueso, son las designaciones de mayor recurrencia en las páginas de la obra.

Mediante lo anterior, Mijares representa la manera en la cual intuye a los victimarios, es decir, como seres totalmente despojados de humanidad, entes escalofriantes que no pueden ser manifestados como personas comunes, individuos perturbadores que desde su nombre contienen al caos y a la maldad, que significan a esta última y la encarnan.

Aunque pareciera que tanto Alan Aguilar como Enrique Mijares son hiperbólicos al personificar a sus protagonistas, las situaciones que narran y los sujetos que describen, no se alejan del marco real. Las formas de tortura materializadas en las víctimas de las cuales los personajes de Enrique Mijares se vanaglorian, ni por asomo son el resultado de la imaginación del autor. Las 
vejaciones descritas en el terreno ficcional, pueden ser corroboradas en textos como Huesos en el desierto de Sergio González Rodríguez y Feminismo y violencia de género de Julia Monárrez.

Sobre el mismo tema, en Los trazos del viento pudiera ser percibido que el autor trata de convertir a las víctimas en mártires, en santas condenadas a una muerte prematura y continua. Pero no es así, Aguilar no eleva a las víctimas al nivel de la perfección, más bien las sublima a través de elementos literarios y estéticos que las configuran como sinónimo de sujetos atropellados por el mal,

"LUCÍA NIÑA DE LOS CANARIOS: Nos encantaría volver a ver a mamá Mari en el reflejo de sus flores y poderle cantar, y poderle decir... que yo también la extraño.” (68)

Resulta claro que la ternura con la cual Alan Aguilar tejió a sus personajes, funciona como una perfecta antítesis para la violencia perturbadora con la cual Enrique Mijares articuló a los suyos, razón por la cual en ambas es posible identificar un discurso de género complementario. En una primera lectura de las obras pudiera parecer que el espectador se encuentra con el mensaje de, "todas las mujeres son víctimas y todos los hombres victimarios"; sin embargo, dicha premisa se modifica si se toma en cuenta que las historias se desarrollan en un contexto sumamente específico: el de los feminicidios de Ciudad Juárez.

La idea anterior refiere a que, aunque en principio es cierto que en las obras un género agrede y el otro es agredido, no es posible interpretar este hecho ni como que todos los hombres son agresores, ni como que todas las mujeres son víctimas. Pues, para que los feminicidios pudieran llevarse a cabo en las obras, fueron necesarias situaciones determinadas y por ello determinantes: primero el contexto social, "people who [live] in Juarez are immediately immersed in a society governed by a maquila logic" (Rodríguez ch. 7); y después el ideológico y 
el cultural, pues como Jane Franco afirma, "the border culture has long idealized the macho and the outlaw, reinforcing a sense of male omnipotence" (223).

De tal modo en las obras analizadas subyace este discurso: específicamente, las mujeres que han sido asesinadas en Ciudad Juárez son víctimas, y sus asesinos son victimarios inhumanos. Sin embargo, aunque dicha idea no puede interpretarse como "todas" y "todos" (nótese que ambas fueron escritas justamente por hombres también de la frontera), la denuncia que existe en tal discurso es clara: la ideología patriarcal asumida y perpetuada, cuando encuentra sustento -sea cual sea-, puede llevarse al extremo y culminar en crímenes de odio de esta índole, como la historia ha comprobado. Y esto último sí que puede y debe generalizarse.

En el punto anterior radica que ni las protagonistas de Aguilar, ni los protagonistas de Mijares presenten resistencia al rol que sus autores les han impuesto. No hay complejidad psicológica en los personajes porque la situación, como la presenta el marco histórico y como la presenta esta literatura, es clara:

[Ciudad Juárez] ha sido testigo por más de una década del exterminio brutal de un centenar de niñas y mujeres convertidas en objetos del deseo sádico sexual de los asesinos, que hasta el momento no sabemos quiénes son. (Monárrez 51)

Por lo anterior, ya que -como fue visto líneas atrás-, los dramaturgos procuran reflejar con fidelidad el perfil de los involucrados, no pueden incluir en éste ni claroscuros ni puntos medios, pues no habría evidencia con la cual sustentar tal complejidad. De las ideas previas, se infiere que es posible justificar el retrato que tanto de las víctimas como de los victimarios los dramaturgos realizan, pues éstos se apegan a las evidencias que tanto el marco teórico como el histórico han otorgado. 
Como ha sido posible percibir, ambas obras comparten la preocupación por mantener en la memoria un tema todavía insoluto. En una entrevista que se realizó a los espectadores al salir de la puesta en escena de Los trazos del viento llevada a cabo en junio de $2008^{11}$ en la ciudad de México y difundida por Alan Aguilar, el periodista Sergio González Rodríguez (quien fue parte de la audiencia), señaló que la puesta en escena "nos pone en una zona de reflexión, pero también en una zona de apreciación estética"; en un tono similar, los demás espectadores entrevistados coincidieron en que "el tema está muy bien cuidado para guiar al corazón", de modo tal que "genera conciencia". A lo anterior se agrega el comentario de la directora Dana Aguilar, quien afirma, "todo teatro es social ... [esta obra] surge como una acción emergente ante todo lo que está pasando", elementos por los cuales se manifiesta el carácter de denuncia de Los trazos del viento.

Un evento similar sucede con Jauría, pues al tener como referencia que para el autor el verdadero teatro

va hasta el borde mismo, se atreve a visitar los extremos, toca fondo, se atreve a rebasar linderos ... se atreve a decir lo que otros callan, a denunciar los acontecimientos de hoy, las historias que resultan incómodas a las buenas conciencias. (citado en Galicia párr. 1)

Es posible inferir que la segunda obra analizada, debido al tema que aborda, tiene también un propósito social. De tal modo, en las obras se revelan dramaturgos comprometidos, conscientes en que el arte y en particular el teatro, son caminos viables para buscar cambios sociales y artísticos.

La maldad, simbolizada por el viento incipiente en la obra de Aguilar -y que en la puesta en escena se personifica como un hombre vestido de negro que

11 La cual se encuentra en el canal de Youtube de Alan Aguilar, https://www.youtube.com/watch?v=U1ebbt9Hzqw. 
resulta de gran impacto para la audiencia- ha demostrado mantener vigencia en el mundo actual, más no hegemonía. La evidencia que es posible erigir a tal premisa consiste en los trabajos imperecederos de aquellos humanistas que, a través de un activismo comprometido, encaminado ya sea a participar en manifestaciones, proponer cambios o hacer arte, se mantienen en pie de lucha para mantener en la memoria temas como el aquí abordado.

Los personajes, como ha sido expuesto, han demostrado ser medios fieles para la representación de los perfiles de los sujetos narrados, pues, ya con sensibilidad y con ternura, o con visceralidad y desapego, los autores lograron edificar a sus protagonistas sobre una base teatral estéticamente sólida, que con verosimilitud y compromiso expone a la realidad a la que alude.

Jauría y Los trazos del viento se constituyen como dos piezas fundamentales en la enredadera de voces que versa sobre aquellos sucesos que, como el feminicidio, deben ser recordados hasta ahuyentar de ellos impunidades y olvidos; si la fe en el cambio de conciencias y en la mejora del mundo algún día se materializa, seguramente en ello el teatro habrá intervenido.

\section{Bibliografía}

Aguilar, Alan. "Los trazos del viento." Hotel Juárez, dramaturgia de feminicidios. México: Siglo XXI, 2008. Print.

- $\quad$ https://www.youtube.com/watch?v=u9mUHi2bYuY. Los trazos del viento 2. Youtube. Web. 16 Jun. 2008.

Beristáin, Helena. Diccionario de poética y retórica. México, D.F.: Porrúa, 2008. Print. 
Fairclough, Norman, Language and Power 2nd edition. London: Longman, 2001. Print.

Franco, Jane. Cruel Modernity. Duke University: Duke Univeristy Press, Durham and London, 2013. Print.

Galicia Velasco, Rocío Judith. "La realidad hipertextual del teatro mexicano. Propuesta teórica de Enrique Mijares". Dramaturgia mexicana.com. 2007. Web. 2 Aug. 2014.

González Rodríguez, Sergio. Huesos en el desierto. Barcelona: Editorial Anagrama, 2002. Print.

Lagarde y de los Ríos, Marcela. "Antropología, feminismo y política: violencia feminicida y derechos humanos de las mujeres". Retos teóricos y nuevas prácticas. Coords. Margaret Bullen, Diez Mingetui Carmen. PDF file.

Mijares, Enrique. "Jauría”. Hotel Juárez, dramaturgia de feminicidios. México: Siglo XXI, 2008. Print.

Mónarrez Fragoso, Julia Estela. Feminismo y violencia de género. PDF file.

Olvera, Ramón Gerónimo. Sólo las cruces quedaron. Chihuahua: Instituto chihuahuense de la cultura, 2013. Print.

Pimentel, Luz Aurora. El relato en perspectiva. México D. F.: Siglo XXI, 2005. Print.

Rodríguez, Ileana. Liberalism at its limits. Crime and terror in the Latin American cultural text. University of Pittsburgh Press, 2009. Kindle Edition. John Beverly, and Sara Castro-Klarén, eds.

Segato, Rita Laura. "Qué es un feminicidio". Fronteras, violencia, justicia: nuevos discursos. México: Universidad Nacional Autónoma de México, 2008. Print.

Tabuenca Córdoba, María Socorro. "Baile de fantasmas en Ciudad Juárez al final/principio del milenio". Más allá de la ciudad letrada: crónicas y espacios urbanos. Ed. Muñoz Boris, Silvia Spitta. Pittsburg, Pa.:

Biblioteca América, 2003. Print. 
CATEDRAL TomAda: Revista de crítica literaria latinoamericana / Journal of Latin American Literary Criticism Enredadera a dos voces, Los trazos del viento y Jauría: el teatro como medio de denuncia y lucha

Washington Valdez, Diana. "Ciudad Juárez y la cultura del sacrificio". Fronteras, violencia, justicia: nuevos discursos. México: Universidad Nacional Autónoma de México, 2008. Print. 